\title{
Fibrous Cap Smooth Muscle Cells in Atherosclerotic Coronary Arteries Do Not Express Pluripotent Stem Cell Markers
}

\author{
Melanie Sullivan and Anthony Zulli \\ College of Health and Biomedicine, Victoria University, McKechnie St, St Albans Campus 3021, Victoria, Australia \\ Correspondence should be addressed to Anthony Zulli; anthony.zulli@vu.edu.au
}

Received 27 March 2013; Revised 17 June 2013; Accepted 17 June 2013

Academic Editor: Hironori Nakagami

Copyright (C) 2013 M. Sullivan and A. Zulli. This is an open access article distributed under the Creative Commons Attribution License, which permits unrestricted use, distribution, and reproduction in any medium, provided the original work is properly cited.

Rupture of the coronary artery fibrous cap is a common cause of myocardial infarction, and bone marrow derived cells could play a role in preventing plaque rupture. It is currently unknown whether smooth muscle cells within coronary artery fibrous cap formation are of mature phenotype. Objective. To characterize cells expressing bone marrow stem cells of embryonic type (ESC) markers in coronary artery fibrous cap formation. Design. New Zealand White rabbits were fed a diet supplemented with $0.5 \%$ cholesterol $+1 \%$ methionine $+5 \%$ peanut oil for 4 weeks and then a normal diet for 9 weeks. The left main coronary artery was excised from the heart, processed for paraffin and immunohistochemistry was performed by standard techniques. Results. Oct-4, SSEA 1, 3, and 4 were all present within in atherosclerotic plaque core, codistributed with RAM-11, and were sparingly found in the fibrous cap, but TRA-1-60 and TRA-1-81 positive cells were scarce. Core but not fibrous cap smooth muscle (SMC $\alpha$ actin+) cells also showed codistribution with ESC markers. Conclusions. These results suggest that smooth muscle cells present in the fibrous cap do not express ESC markers, indicative of a mature cell.

\section{Introduction}

Rupture of coronary artery fibrous cap is a major cause of myocardial infarct [1]. Inhibition of the HMG CoA reductase enzyme and renin angiotensin system have been one of the most successful therapies in reducing this burden, possibly by increasing the formation of a stable fibrous cap. Interestingly, stem cells can be regulated by the same pharmacological therapy, providing a possible explanation as to the beneficial effects of treatments [2]. For example, simvastatin has been shown to normalise endothelial progenitor cells in obese patients to those observed in nonobese controls [3] and angiotensin II receptor blockers increased endothelial progenitor cells in diabetic patients [4], and modulation of these types of cells is also observed with angiotensin converting enzyme inhibitors [5]. Thus, the characterization of stem cell populations in coronary artery disease will aid in understanding whether standard pharmacological treatments can affect the population of such undifferentiated cells. Recent studies have suggested that the origin of smooth muscle cells in atherosclerotic fibrous caps might not be from the circulation [6] as had been enthusiastically embraced but derive from the local medial SMC layer $[7,8]$. Thus, in this study, it was hypothesised that if smooth muscle cells originated from the circulation and were of primitive type, then the cells in the fibrous cap should express markers of primitive cell origin.

Adult bone marrow harbours several population of stem cells, such as endothelial progenitor cells, mesenchymal stromal cells, and very small embryonic-like cells which all express markers of pluripotency $[9,10]$. For example, human very small embryonic-like cells express a range of markers, including Oct-4, SSEA-4 $[9,10]$, endothelial progenitor cells express CD34, CD133, and the VEGF receptor [11], and mesenchymal stromal cells extracted from human placenta express SSEA-1, SSEA-3, SSEA-4, Tra-1-60, Tra1-81, and Oct4 [12]. We have reported the positive identification of markers of primitive cell origin and endothelial precursor cells in human and rabbit atherosclerosis. CD34+ cells [13] and embryonic stem cell markers, octomer-4 (Oct-4), the SSEA 1,3, and 4, TRA-1-60, and TRA-1-81 [14] have been identified 
in rabbit atherosclerotic vessels and human diseased arteries [15]. Oct- 4 is a transcription factor, and its downregulation is believed to trigger the differentiation of the undifferentiated cell [16]. Stage-specific embryonic antigens (SSEAs) are associated with cell adhesion, migration, and differentiation and are often differentially expressed during development [17], whereas tumor rejector antigens (TRAs) were first developed for antibody-based treatments for cancer [18].

As the identification and localisation of cells expressing markers of pluripotency within coronary artery atheromatous plaques have not yet been performed, we sought to use immunohistochemistry to identify the specific location of such cells within the fibrous cap and core of the atherosclerotic lesion and to regionally compare this with macrophages and smooth muscle cells.

\section{Methods}

Male New Zealand White rabbits at three months of age were fed a normal rabbit chow diet supplemented with $0.5 \%$ cholesterol plus $1 \%$ methionine plus $5 \%$ peanut oil for 4 weeks and then a normal chow diet for 9 weeks to induce fibrous cap formation [19]. The animals were housed in individual cages and maintained at a constant temperature of approximately $21^{\circ} \mathrm{C}$. Food and water were supplied ad libitum. The experiments were carried out according to the National Health and Medical Research Council "Australian Code of Practice for the Care and Use of Animals for Scientific Purposes" (6th Edition, 1997). The animals were sacrificed by an overdose of ketamine and xylazine, the hearts were removed, and the left main coronary artery was excised, fixed in $4 \%$ paraformaldehyde solution in 1xPBS overnight, processed for paraffin, and mounted on one paraffin block [19]. The block was mounted on a microtome (Microm, HM325, ThermoScientific Australia) and $5 \mu \mathrm{m}$ ribbons were collected and placed onto a $48^{\circ} \mathrm{C}$ hot water bath [14]. Once sections expanded to normal block size, serial sections were collected onto microscope slides, labelled, and dried in a $37^{\circ} \mathrm{C}$ oven overnight. Slides were then stored in an airtight container.

2.1. Immunohistochemistry. As double labelling techniques cannot be used in rabbit models, as a mouse and rabbit primary antibody is necessary, we used serial sections to identify cells. The use of an anti-rabbit secondary antibody will lead to high nonspecific binding of IgG present in cells.

Oct-4, SSEA1, SSEA3, SSEA4, TRA-1-60, and TRA-181 monoclonal antibodies were purchased from Millipore USA [14]. RAM-11 was purchased from DAKO cytomation and HHF-35 (rabbit SMC $\alpha$ actin) from Millipore, USA. All primary antibodies were diluted 1:100 and incubated overnight. For the negative control, a monoclonal antibody to Aspergillus niger glucose oxidase (DAKO Corporation, USA) was diluted 1:20 and incubated overnight. Then, immunohistochemistry was performed as previously described in our laboratory $[19,20]$. The block was mounted on a microtome (Microm, HM325, ThermoScientific Australia) and $5 \mu \mathrm{m}$ ribbons were collected and placed onto a $48^{\circ} \mathrm{C}$ hot water bath [14]. Once sections expanded to normal block size, serial sections were collected onto microscope slides, labelled, and dried in a $37^{\circ} \mathrm{C}$ oven overnight. Slides were then stored in an airtight container.

\section{Results}

In the left main coronary artery, RAM-11 positive macrophages were observed throughout the plaque (Figure 1(a)) and also sporadically within the fibrous cap (magnified images beneath Figure 1(a)). Oct-4 showed a similar pattern and codistributed with RAM-11 as observed (Figure 1(b) and magnified images beneath (b), dashed circles). SMC $\alpha$ actin positive cells (HHF35) were identified as spindle shaped cells in the fibrous cap, as well as macrophage-like cells that coexpressed Oct-4 within cells of the fibrous cap (arrows, Figure 1(c) and images beneath (c)). Coexpression of SMC $\alpha$ actin, RAM-11, Oct-4, and SSEA-4 (Figures 1(d) and 2(a)) was observed in the core (Figures 1(a), 1(b), 1(c), and 1(d)).

Interestingly, the spindle shaped SMC $\alpha$ actin positive cells within the cap (Figure 1(c) bottom image) did not show reactivity to Oct- 4 or other ESC markers tested (Figures $2(\mathrm{a})-2(\mathrm{~g})$ ), although nonspindle shaped $\mathrm{SMC} \alpha$ actin positive cells within the core were immunoreactive with SSEA1, 3, 4. In addition, the endothelial layer overlying the fibrous cap did show positive immunoreactivity Oct-4, SSEA-1, 3, and 4 . This staining was present in specific "endothelial like" cells overlying the cap (Figures 2(c) and 2(d)) as well as the endothelial layer (Figures 2(b)-2(f)).

Tra-1-60 (Figure 2(c)) and Tra-1-81 (Figure 2(g)) showed no positive endothelial staining cells and no positive core staining cells; however, specific single cells were present either overlying plaques (Figure 2(c) insert) or just beneath the endothelium (Figure 2(g)), and these cells codistributed with RAM-11 (Figure 1(a) bottom image), indicative of macrophages.

Negative control showed no immunoreactivity (Figure 2(h)).

\section{Discussion}

The major finding in this investigation is that the fibrous cap formed in the left main coronary artery of rabbits contain spindle shaped SMC $\alpha$ actin positive cells that do not codistribute with ESC markers. However, the core contains abundant cells positive for ESC markers and SMC $\alpha$ actin positive cells. Furthermore, Tra-1-81 and 1-60 are scarcely present in plaques.

The beneficial role of stem cells in atherogenesis remains unclear. Although clinical studies show a possible beneficial role for stem cell therapy in cardiac repair [21], the opposite appears to hold true in animal model studies of atherosclerotic disease. For example, Silvestre and colleagues show that the injection of bone marrow-derived mononuclear cells increased aortic sinus atherosclerotic lesions up to $72 \%$ [22]. The authors argue that as plaque collagen and smooth muscle cells also increase, plaque stability was uncompromised. On 

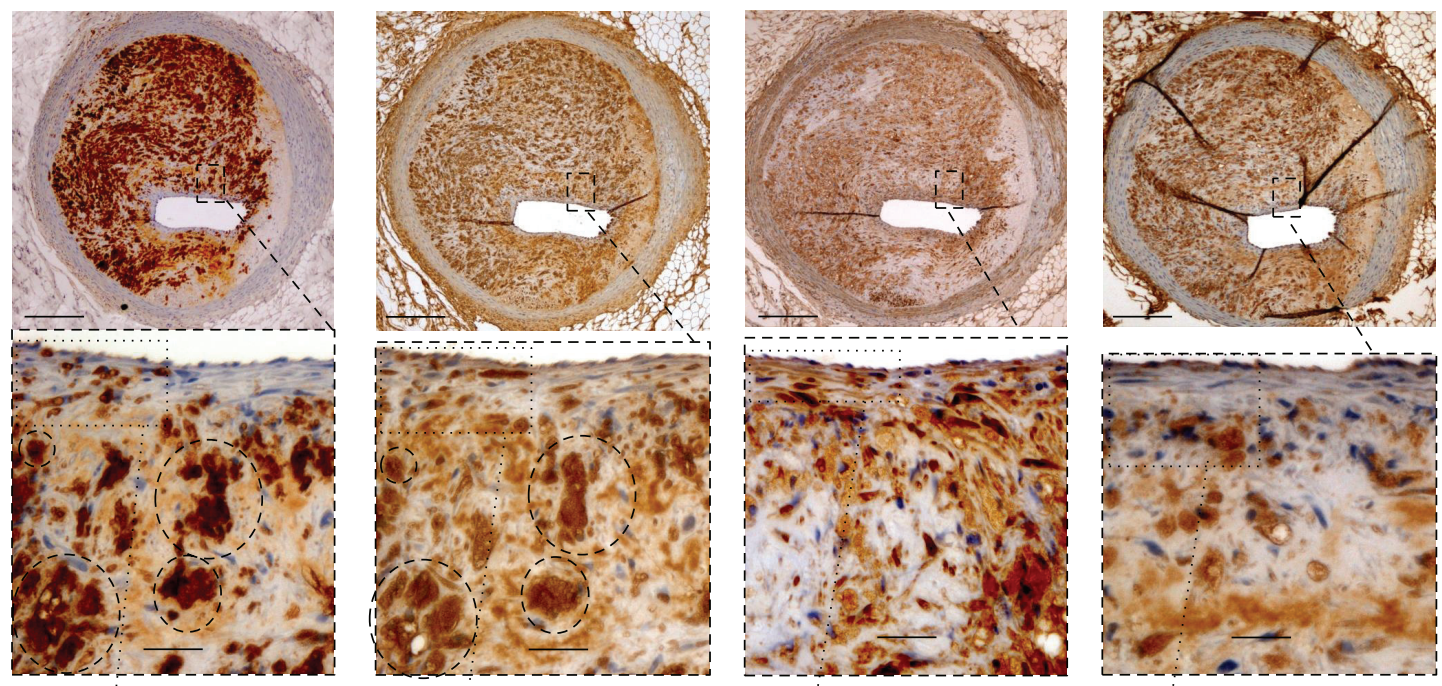

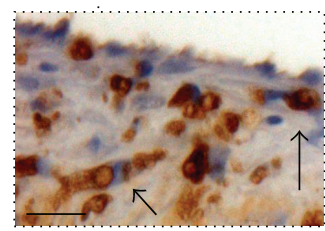

(a) RAM-11

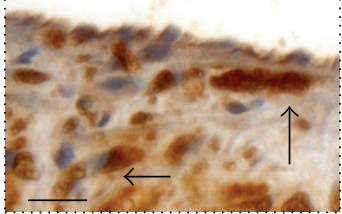

(b) Oct-4

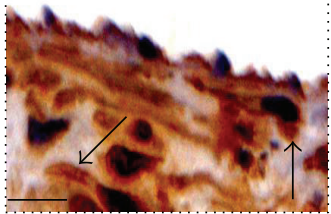

(c) $\mathrm{SMC} \alpha \mathrm{a}$

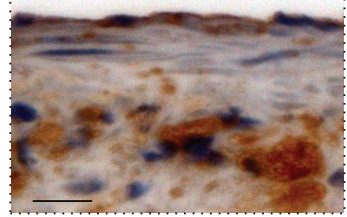

(d) SSEA-4

FIGURE 1: Photomicrographs of serial adjacent sections of the left main coronary artery. Photos are arranged in columns. Macrophage (RAM11) positive cells are abundant throughout the plaque $((\mathrm{a}), \times 40$, scale bar $250 \mu \mathrm{m})$, and also sporadically within the fibrous cap ((a), exploded view, $\times 400$, scale bar $18 \mu \mathrm{m}$ ). These results were very similar to Oct- 4 staining (b), indicative that macrophages might be primitive cells (arrows and dashed circles). In addition, SMC $\alpha$ actin positive cells were visible throughout the plaque (c), specifically represented as spindle shaped cells in the formed cap ((c), exploded view, scale bar $8 \mu \mathrm{m})$, as well as overlying the endothelial layer. SSEA-4 positive immunolabled cells were also present in the endothelial layer and coronary artery core, and this was similar to RAM-11, Oct-4, and SMC $\alpha$ actin positive cells. No spindle shaped cells were present in the coronary artery fibrous cap that also reacted with any ESC marker.

the other hand, George and colleagues show that endothelial progenitor cell transfer caused increased aortic sinus atherosclerotic lesion size, as well as decreasing collagen content, increasing ox-LDL and CD-3 positive lymphocytes, indicative of a more vulnerable plaque [23]. Thus, novel animal models are necessary to help elucidate which type of stem cells is vital for the regression and stabilization of coronary artery disease. In this regard, we report that human coronary artery atherosclerotic disease contains cells expressing ESC markers [15] and now an animal model in rabbit is developed to help elucidate the role of these cells in coronary artery disease.

The origin of smooth muscle cells within atherosclerotic plaques is still unclear. Although initially it was suggested that plaque remodelling was governed by local proliferating plaque SMCs [24], further studies suggested these cells were from the circulation [6]. However, these studies have now been refuted, and current data have returned the emphasis on local SMC $[7,8]$. Although methodological differences between these studies are of importance (harsh surgical manipulation), we have used a gentle dietary manipulation technique to address this question. In our study, we report that spindle shaped smooth muscle cells that have formed in the fibrous cap in the coronary artery do not express any stem cell markers tested; however, other cells in the plaque express both smooth muscle alpha actin and stem cell markers. This data supports the hypothesis that fibrous cap smooth muscle cells might not originate from the circulation however, further experiments aimed at tracking blood borne ESC+ cells will help understand the role of these cells in atherogenesis.

The ability of cells in the blood vessel to acquire such markers, upregulate such markers, or downregulate such markers cannot be discounted. Cell fusion is a process whereby cells can combine and share genetic material [25] thus, it would be possible that cells entering from the lumen could combine with cells present in the wall and express these markers. In addition, evidence also exists whereby cells can be stimulated to express embryonic markers [26], or might be stimulated to switch the phenotype to a "synthetic" cell, rather than "contractile" [27, 28]. Thus, further experiments designed at identifying the origin of such cells are warranted. Moreover, such cells could downregulate the expression of these markers once the cells have homed into their specific location, as it is clear that cells loose these makers during differentiation $[29,30]$. 

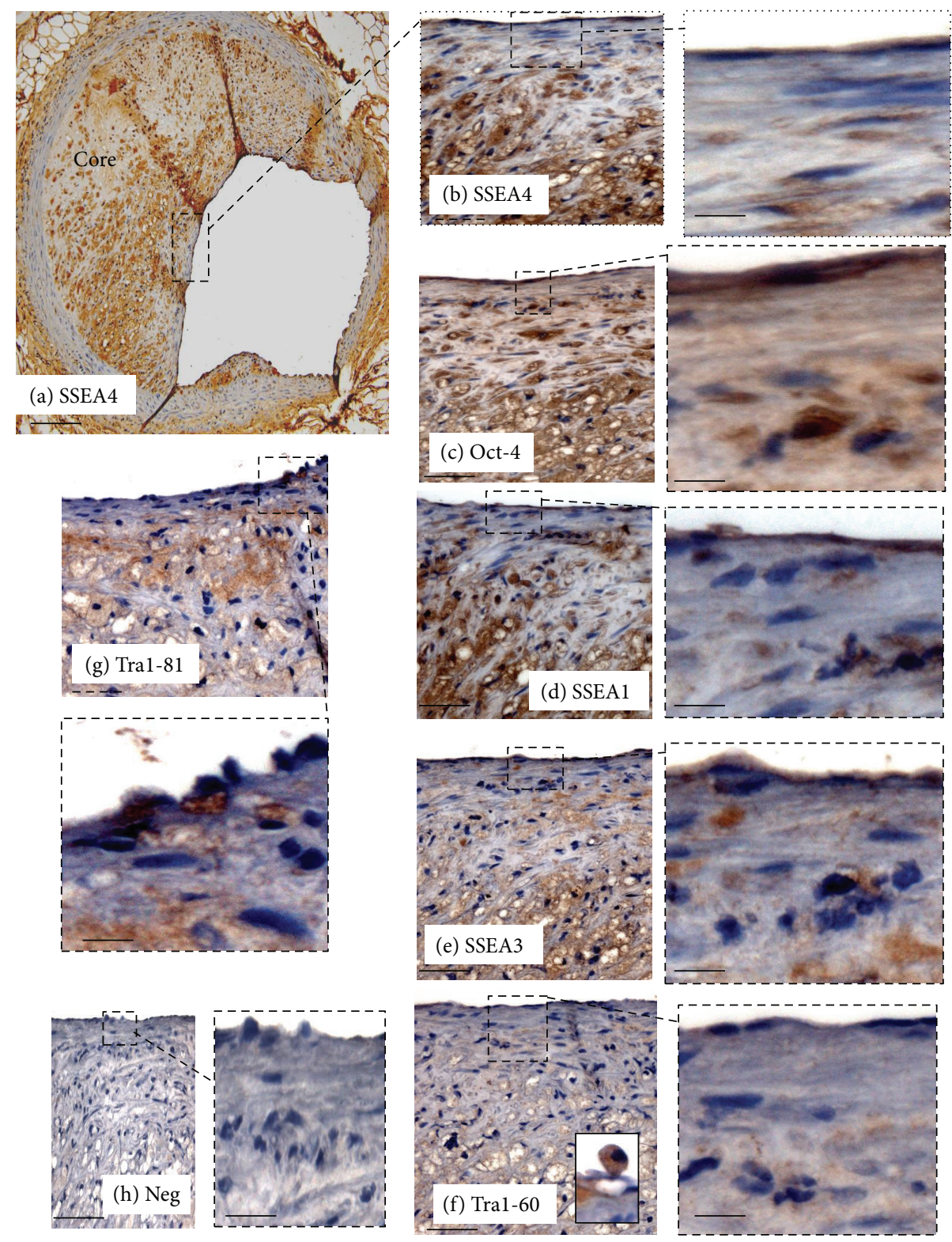

FIGURE 2: Photomicrographs of serial adjacent sections of the left main coronary artery showing codistribution of SSEA-4, Tra-1-60, Oct-4, SSEA-1, SSEA-3, and Tra1-81. SSEA4 positive cells were observed throughout the plaque ((a), scale bar $165 \mu \mathrm{m})$ as also shown in Figure 1(d). Clear endothelial-like cells were present overlying the fibrous cap ((b), exploded view, scale bar $33 \mu \mathrm{m}$, exploded view scale bar $15 \mu \mathrm{m})$; however, not all cells that expressed SSEA-4 codistributed with Oct-4 ((c), scale bar $33 \mu \mathrm{m}$, exploded view scale bar $15 \mu \mathrm{m})$, although the copresence of endothelial SSEA1/SSEA3 was observed (Figures 2(d) and 2(e), scale bar $33 \mu \mathrm{m}$, exploded view scale bar $15 \mu \mathrm{m}$ ). Interestingly, there were no core cells that were positive for Tral-60 (f) nor Tral-81 (g) but were scarcely present either overlying the endothelial layer ((f), Tral-60 insert, scale bar $33 \mu \mathrm{m}$, exploded view scale bar $15 \mu \mathrm{m})$ or just present beneath the endothelium ( $(\mathrm{g})$, scale bar $33 \mu \mathrm{m}$, exploded view scale bar $15 \mu \mathrm{m})$. Negative control shows no positive signal ((h), scale bar $60 \mu \mathrm{m}$, exploded view scale bar $20 \mu \mathrm{m})$. As is also observed, no ESC positive spindle shaped cells are present in the fibrous cap.

In these experiments using serial sections cut at five microns, there is a possibility that the cells which are identified as staining positive for each specific marker might not be the identical cells in the serial section, even though the staining pattern is very similar (dashed circles, Figures 1(a) and 1(b)). Thus, the results presented here clearly indicate that further experiments aimed at tracking specific populations of stem cells and determining their final destination will offer great insight into the origin of smooth muscle cells in atherosclerotic plaques.

In summary, we show that cells expressing stem cell markers are present within coronary artery plaques, which could be very small embryonic-like cells and mesenchymal stromal cells. In addition, it is shown that smooth muscle cell $\alpha$ actin positive cells within the fibrous cap of coronary artery plaques do not express these stem cell markers, 
although macrophages (RAM-11+) and smooth muscle cells $\alpha$ actin positive cells within the same plaques do express these markers. This data indicates that the spindle shaped, smooth muscle $\alpha$ actin positive cells within fibrous cap are a mature cell type and are most probably incapable of further differentiation. In addition, it is suggested that this animal model could be used to further study the role of pharmacotherapy in the regulation of such cells, which might be translatable to human coronary artery fibrous cap formation and thus prevention of plaque rupture.

\section{Conflict of Interests}

The authors have no conflicts of interest.

\section{Acknowledgments}

This work was supported by the National Heart Foundation of Australia and the National Health \& Medical Research Council of Australia. The authors would like to thank Professor David Hare, Department of Cardiology, Austin Health, Heidelberg Australia, for providing infrastructure support.

\section{References}

[1] R. Corti, M. E. Farkouh, and J. J. Badimon, "The vulnerable plaque and acute coronary syndromes," American Journal of Medicine, vol. 113, no. 8, pp. 668-680, 2002.

[2] T. Umemura and Y. Higashi, "Endothelial progenitor cells: therapeutic target for cardiovascular diseases," Journal of Pharmacological Sciences, vol. 108, no. 1, pp. 1-6, 2008.

[3] P. E. Westerweel, F. L. J. Visseren, G. R. Hajer et al., "Endothelial progenitor cell levels in obese men with the metabolic syndrome and the effect of simvastatin monotherapy vs. simvastatin/ezetimibe combination therapy," European Heart Journal, vol. 29, no. 22, pp. 2808-2817, 2008.

[4] F. H. Bahlmann, K. de Groot, O. Mueller, B. Hertel, H. Haller, and D. Fliser, "Stimulation of endothelial progenitor cells: a new putative therapeutic effect of angiotensin II receptor antagonists," Hypertension, vol. 45, no. 4, pp. 526-529, 2005.

[5] C.-H. Wang, S. Verma, I.-C. Hsieh et al., "Enalapril increases ischemia-induced endothelial progenitor cell mobilization through manipulation of the CD26 system," Journal of Molecular and Cellular Cardiology, vol. 41, no. 1, pp. 34-43, 2006.

[6] M. Sata, A. Saiura, A. Kunisato et al., "Hematopoietic stem cells differentiate into vascular cells that participate in the pathogenesis of atherosclerosis," Nature Medicine, vol. 8, no. 4, pp. 403-409, 2002.

[7] J. F. Bentzon, C. S. Sondergaard, M. Kassem, and E. Falk, "Smooth muscle cells healing atherosclerotic plaque disruptions are of local, not blood, origin in apolipoprotein E knockout mice," Circulation, vol. 116, no. 18, pp. 2053-2061, 2007.

[8] J. F. Bentzon, C. Weile, C. S. Sondergaard, J. Hindkjaer, M. Kassem, and E. Falk, "Smooth muscle cells in atherosclerosis originate from the local vessel wall and not circulating progenitor cells in apoE knockout mice," Arteriosclerosis, Thrombosis, and Vascular Biology, vol. 26, no. 12, pp. 2696-2702, 2006.

[9] W. Wojakowski, M. Kucia, R. Liu et al., "Circulating very small embryonic-like stem cells in cardiovascular disease," Journal of
Cardiovascular Translational Research, vol. 4, no. 2, pp. 138-144, 2011.

[10] W. Wojakowski, M. Kucia, E. Zuba-Surma et al., "Very small embryonic-like stem cells in cardiovascular repair," Pharmacology and Therapeutics, vol. 129, no. 1, pp. 21-28, 2011.

[11] S. Berger and L. Lavie, "Endothelial progenitor cells in cardiovascular disease and hypoxia-potential implications to obstructive sleep apnea," Translational Research, vol. 158, no. 1, pp. 1-13, 2011.

[12] Y.-C. Huang, Z.-M. Yang, X.-H. Chen et al., "Isolation of mesenchymal stem cells from human placental decidua basalis and resistance to hypoxia and serum deprivation," Stem Cell Reviews and Reports, vol. 5, no. 3, pp. 247-255, 2009.

[13] A. Zulli, B. F. Buxton, M. J. Black, and D. L. Hare, " $\mathrm{CD}_{34}$ Class III positive cells are present in atherosclerotic plaques of the rabbit model of atherosclerosis," Histochemistry and Cell Biology, vol. 124, no. 6, pp. 517-522, 2005.

[14] A. Zulli, B. F. Buxton, M. J. Black, and D. L. Hare, "Embryonic stem cells markers are present within rabbit atherosclerotic plaques," Histology and Histopathology, vol. 23, no. 6, pp. 741746, 2008.

[15] A. Zulli, B. F. Buxton, M. Merrilees, and D. L. Hare, "Human diseased arteries contain cells expressing leukocytic and embryonic stem cell markers," Human Pathology, vol. 39, no. 5, pp. 657-665, 2008.

[16] M. Pesce and H. R. Schöler, "Oct-4: gatekeeper in the beginnings of mammalian development," Stem Cells, vol. 19, no. 4, pp. 271-278, 2001.

[17] M. Yanagisawa and R. K. Yu, "The expression and functions of glycoconjugates in neural stem cells," Glycobiology, vol. 17, no. 7, pp. 57R-74R, 2007.

[18] E. Gilboa, “The makings of a tumor rejection antigen," Immunity, vol. 11, no. 3, pp. 263-270, 1999.

[19] A. Zulli and D. L. Hare, "High dietary methionine plus cholesterol stimulates early atherosclerosis and late fibrous cap development which is associated with a decrease in GRP78 positive plaque cells," International Journal of Experimental Pathology, vol. 90, no. 3, pp. 311-320, 2009.

[20] A. Zulli, S. Rai, B. F. Buxton, L. M. Burrell, and D. L. Hare, "Colocalization of angiotensin-converting enzyme 2-, octomer4- and CD34-positive cells in rabbit atherosclerotic plaques," Experimental Physiology, vol. 93, no. 5, pp. 564-569, 2008.

[21] C. Urbich and S. Dimmeler, "Endothelial progenitor cells: characterization and role in vascular biology," Circulation Research, vol. 95, no. 4, pp. 343-353, 2004.

[22] J.-S. Silvestre, A. Gojova, V. Brun et al., "Transplantation of bone marrow-derived mononuclear cells in ischemic apolipoprotein E-knockout mice accelerates atherosclerosis without altering plaque composition," Circulation, vol. 108, no. 23, pp. 28392842, 2003.

[23] J. George, A. Afek, A. Abashidze et al., "Transfer of endothelial progenitor and bone marrow cells influences atherosclerotic plaque size and composition in apolipoprotein E knockout mice," Arteriosclerosis, Thrombosis, and Vascular Biology, vol. 25, no. 12, pp. 2636-2641, 2005.

[24] P. Libby, "Inflammation in atherosclerosis," Nature, vol. 420, no. 6917, pp. 868-874, 2002.

[25] S. Bonde, M. Pedram, R. Stultz, and N. Zavazava, "Cell fusion of bone marrow cells and somatic cell reprogramming by embryonic stem cells," FASEB Journal, vol. 24, no. 2, pp. 364$373,2010$. 
[26] M. Wang, J. Zhang, L.-Q. Jiang et al., "Proinflammatory profile within the grossly normal aged human aortic wall," Hypertension, vol. 50, no. 1, pp. 219-227, 2007.

[27] J. H. Campbell and G. R. Campbell, "The cell biology of atherosclerosis-new developments," Australian and New Zealand Journal of Medicine, vol. 27, no. 4, pp. 497-500, 1997.

[28] R. J. Dilley, J. K. McGeachie, and F. J. Prendergast, "A review of the proliferative behaviour, morphology and phenotypes of vascular smooth muscle," Atherosclerosis, vol. 63, no. 2-3, pp. 99-107, 1987.

[29] K. Noaksson, N. Zoric, X. Zeng et al., "Monitoring differentiation of human embryonic stem cells using real-time PCR," Stem Cells, vol. 23, no. 10, pp. 1460-1467, 2005.

[30] J. R. Tejedo, R. Tapia-Limonchi, S. Mora-Castilla et al., "Low concentrations of nitric oxide delay the differentiation of embryonic stem cells and promote their survival," Cell Death and Disease, vol. 1, no. 10, article e80, 2010. 


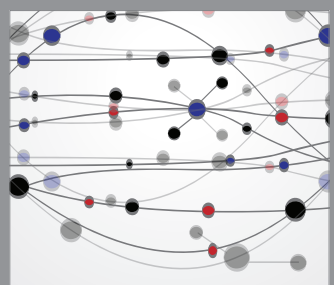

The Scientific World Journal
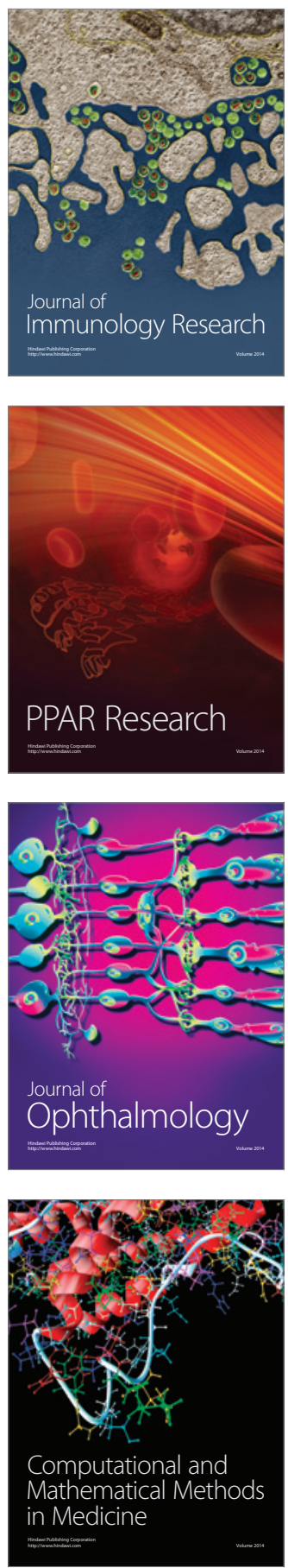

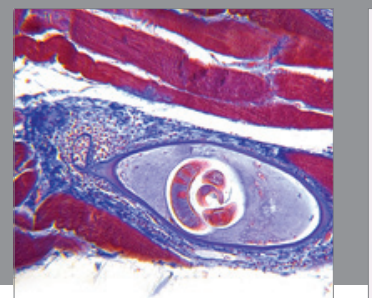

Gastroenterology

Research and Practice
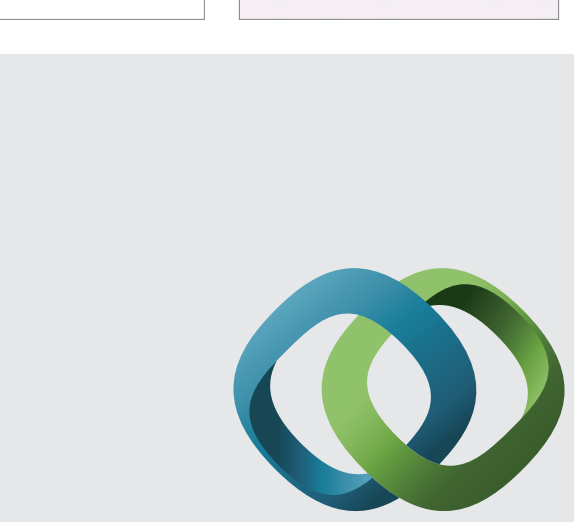

\section{Hindawi}

Submit your manuscripts at

http://www.hindawi.com
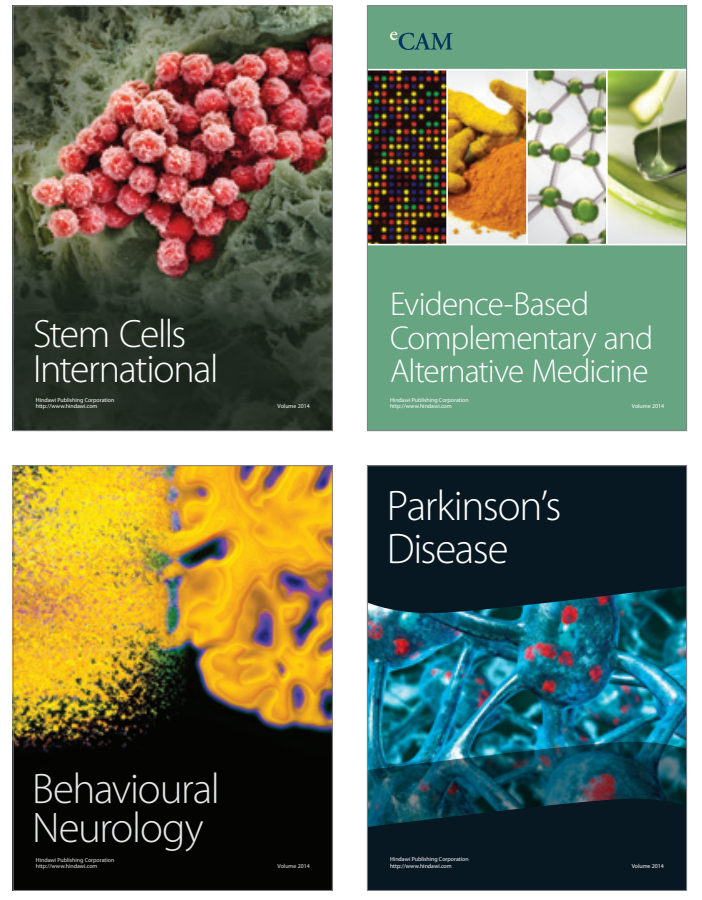
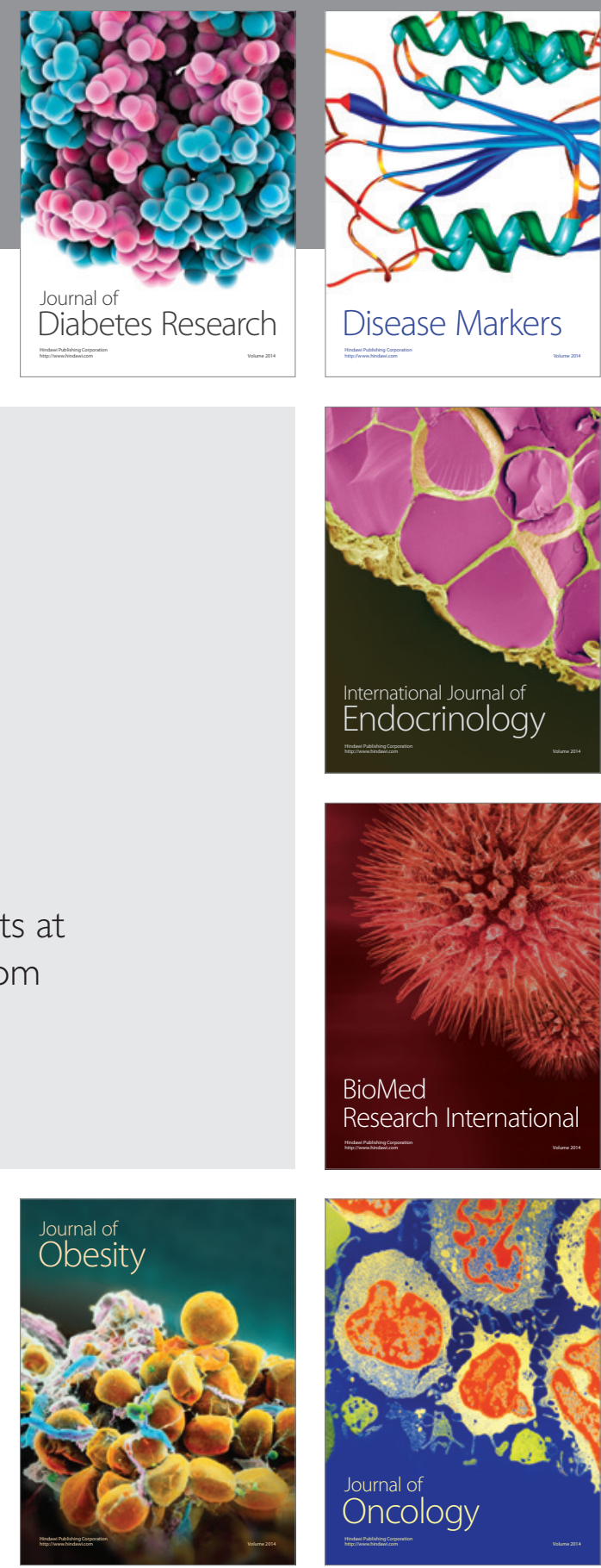

Disease Markers
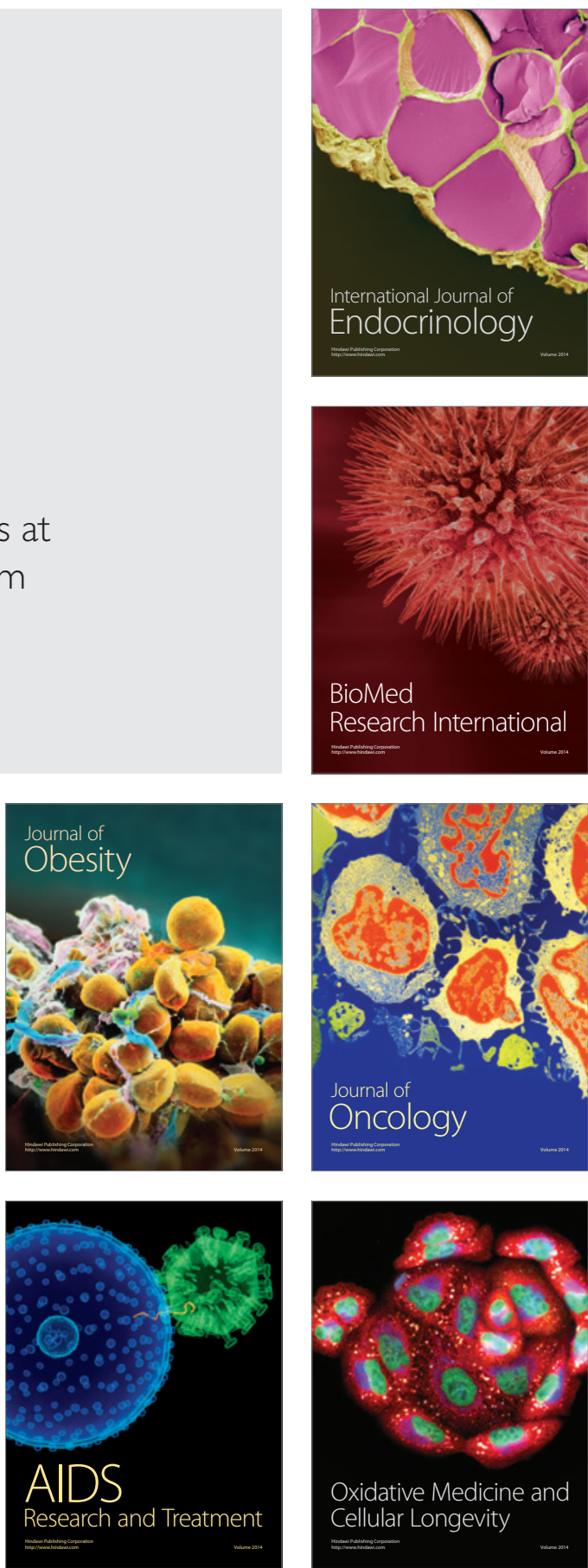